\title{
Soil quality and C-S-R fungal communities in monoculture plantations after conversion from subtropical forest
}

Ting Liu ${ }^{1}$, Xiao $\mathrm{Wu}^{1}$, Huangwei $\mathrm{Li}^{1}$, Chen Ning ${ }^{1}$, Yong $\mathrm{Li}^{1}$, Xuyuan Zhang ${ }^{1}$, Jinsong $\mathrm{He}^{1}$, Filimonenko Ekaterina ${ }^{2}$, Shu Chen ${ }^{3}$, Xiaoyong Chen ${ }^{4}$, David Gibson $^{3}$, Yakov Kuzyakov ${ }^{5}$, and Wende Yan $^{1}$

${ }^{1}$ Central South University of Forestry and Technology

${ }^{2}$ Tyumen State University

${ }^{3}$ Southern Illinois University Carbondale

${ }^{4}$ Governors State University

${ }^{5}$ Institute of Physicochemical and Biological Problems of Soil Science. Russian Academy of Sciences

December 29, 2021

\begin{abstract}
Intensive clear cutting of natural forests and conversion to monoculture plantations are ongoing worldwide, leading to degradation of soil quality and microbial functions. Here, we compared soil quality index (SQI) and fungal community in a natural forest (Forest) and four 5-year-old monoculture plantations, including Camellia oleifera (Oil), Amygdalus persica (Peach), Myrica rubra (Berry) and Cunninghamia lanceolata (Fir), in a subtropical region of China. After conversion, soil $\mathrm{pH}$ rose up to 0.31 , but organic carbon, total nitrogen, sucrase, acid protease, glutaminase and phosphatase activities decreased by $83 \%, 59 \%$, $43 \%, 31 \%, 64 \%, 66 \%$ and $77 \%$, respectively, in the plantations. Correspondingly, the SQI dropped by $65 \%$. High-throughput sequencing of the ITS1 region demonstrated an increase in $\alpha$-diversity and a striking difference in $\beta$-diversity following conversion. Changes in the dominant fungal taxa following forest conversion to plantations was interpreted by Grime's C-S-R life history framework. Conversion increased the fungal groups with stress-tolerant (S) and ruderal (R) strategies - mainly copiotrophic saprophytes, such as Ascomycota and Zygomycota, but decreased the fungal groups with competitor (C) strategies mainly oligotrophic saprophytes and mycorrhizal fungi, such as Basidiomycota. Genera affiliated to those phyla including Pseudophialophora, Rhytisma increased, but Russula decreased. Redundancy analysis and structural equation modeling indicated that the diversity and composition of fungal communities changed with soil quality degradation, which were mainly driven by increased soil $\mathrm{pH}$, decreased available carbon and nutrients $(\mathrm{N}, \mathrm{P})$, and related enzymes activities.
\end{abstract}

\section{Introduction}

Worldwide, half of primary and secondary forests, which are crucial for maintaining biodiversity and ecosystem functions, are being converted into monoculture plantations for the cultivation of timber, fuel materials and other commodities. The annual expanding rates of monoculture plantations have increased to $2 \%$ over the past 25 years (FAO, 2015). Most conversion from natural forests to plantations has occurred in subtropical regions(Lan et al., 2021). Such conversion results in alterations of ecosystem services and functions along with changes in plant diversity and soil nutrients loss (Krashevska, Klarner, Widyastuti, Maraun, \& Scheu, 2015; Yang, Zhu, Xu, \& Zheng, 2018). Soil quality is defined as the capacity to sustain biological productivity, maintain environmental quality, and promote plant and animal health (Doran \& Parkin, 1996). Various methods such as visual qualitative and quantitative approaches have been used to assess soil quality (Bünemann et al., 2018; Yakov et al., 2020). Quantitative evaluation incorporates chemical, physical and 
biological indicators into the calculation of soil quality index (SQI). Forest conversion may lead to reduced vegetation coverage and forest productivity, soil quality deterioration and erosion (Guillaume, Damris, \& Kuzyakov, 2015), all of which will have a negative impact on soil quality and health (Zarafshar et al., 2020). Intensive management and short rotations are employed during conversion, including site reclamation, clear-cutting, residue mulching, herbicide weeding and fertilization. These practices can modify soil quality, but the consequences for microorganisms and nutrient cycling are not clear (Armenise, Redmile-Gordon, Stellacci, Ciccarese, \& Rubino, 2013). Thus, comprehensive and quantitative studies are needed to better understand the impacts of forest conversion on soil quality and functions in subtropical areas.

In forest ecosystems, fungi play fundamental ecological roles as decomposers, symbionts, and tree pathogens (Uroz, Buée, Deveau, Mieszkin, \& Martin, 2016). They regulate organic matter decomposition and nutrient cycling, and stimulate plant growth (Nakayama, Imamura, Taniguchi, \& Tateno, 2019). The establishment of fungal community is determined by both abiotic (i.e. climate, spatial heterogeneity and edaphic conditions) (Steidinger et al., 2019; van der Linde et al., 2018) and biotic (i.e. host species) factors (Duhamel et al., 2019). The conversion from natural forest to plantations is accompanied by changes in the identity and diversity of host tree species and soil properties, thereby affecting the fungal community and tropical-guild composition (Mcguire et al., 2015). Compared with extensive studies on bacterial communities (Kerfahi, Tripathi, Dong, Go, \& Adams, 2016; Liu et al., 2020), only a few studies have evaluated the response of soil fungi to forest conversion. In addition, microbial activity is a valuable indicator of soil quality (Bünemann et al., 2018). For instance, microorganisms can maintain soil P bioavailability (Wu et al., 2019) and alleviate N limitations (Johnson, Rowland, Corkidi, \& Allen, 2008). Hence, it is necessary to evaluate the impacts of forest conversion on the fungal community, which play a vital role in shaping ecosystem functions (e.g., soil nutrient cycling, carbon sequestration).

The aim of our study was to quantify the changes in soil quality and the fungal community following forest conversion. Physico-chemical and biological properties as well as the microbial community composition were measured under a natural forest and four monoculture plantations common for subtropical climate. The objectives were as follows: (1) To investigate the impacts of forest conversion on soil quality and assess the main influencing factors; (2) To evaluate the differences in diversity, composition, and key taxa of fungal community after conversion; (3) To clarify the relationship between soil quality and the fungal community, and explore main driving factors of community changes after conversion.

\section{Materials and methods}

\subsection{Study site and sampling}

The study sites were located in Lutou National Station for Scientific Observation and Research of Forest Ecosystems, Hunan Province, Central South China (11351'52" 113deg58'24"E, 28deg31'17" 28deg38'00"N). The region has a typical mid-subtropical monsoon climate with an annual temperature of $15.8 \operatorname{deg} \mathrm{C}$ and an annual precipitation of 1,450 mm. The soils are characterized as Ferric and Orthic Acrisols (Liu et al., 2020). The subtropical natural forest is dominated by Cinnamomum camphora, Liquidambar formosana, Pinus massoniana, Photinia serratifolia, Ilex chinensis ,Broussonetia papyrifera, Loropetalum chinense and Camellia japonica. A large area of the natural forest (Forest) was cleared and reclaimed to monoculture plantations including Camellia oleifera (Oil), Amygdalus persica (Peach), Myrica rubra (Berry) and Cunninghamia lanceolata (Fir) in 2013 (Liu et al., 2020). After conversion, management practices such as site reclamation, fertilization and weeding were adopted. For the Berry and Peach plantations, 4,356 $\mathrm{kg} \mathrm{ha}^{-1}$ $\mathrm{yr}^{-1}$ organic fertilizers (manure) were applied in October, and $545 \mathrm{~kg} \mathrm{ha}^{-1} \mathrm{yr}^{-1}$ compound mineral fertilizers $\left(\mathrm{N} / \mathrm{P} / \mathrm{K}\right.$ ratios: 1:1:2) were additionally applied to the Peach plantation in July each year. Only $163 \mathrm{~kg} \mathrm{ha}^{-1}$ $\mathrm{yr}^{-1}$ compound mineral fertilizers were applied to the Oil plantation in May each year. The Fir plantation was subject to no management practice.

In November 2018, three replicate plots (10 m x $10 \mathrm{~m}$ each one) were randomly established for each forest type according to slope. After removing the litter layer within each plot, soil was sampled from the 0-20 $\mathrm{cm}$ layer, homogenized and sieved with a 2-mm mesh. In total, 15 composite soil samples were divided into 
three parts: one was dried at room temperature for soil physico-chemical analysis; the other two were kept at 4 and -80 for enzyme activity and molecular analysis, respectively.

\subsection{Analysis of soil}

\section{physico-chemical properties and enzyme activities}

Soil bulk density (BD) and moisture (SWC) were measured with a bulk density ring and conventional dry wet weight methods, respectively. Soil $\mathrm{pH}$ was measured at a soil-to-water ratio of 1:2.5 (w/v) with a pH meter (FE20K, Mettler Toledo, China). Organic carbon (SOC) was determined using the dichromate oxidation method. Dissolved organic carbon (DOC) was extracted by potassium sulfate $\left(0.5 \mathrm{mmol} \mathrm{L}^{-1}\right)$. Total nitrogen (TN) was determined according to semi-micro Kjeldahl method. Ammonium nitrogen $\left(\mathrm{NH}_{4}{ }^{+}\right)$and nitrate nitrogen $\left(\mathrm{NO}_{3}{ }^{-}\right)$were measured by a continuous flow analyzer (Skalar Analytical B.V, SAN++). Total phosphorus (TP) and available phosphorus (AP) were assayed by the molybdenum antimony anticolorimetric method. Total potassium (TK), available potassium (AK), exchangeable calcium (Ca) and magnesium $(\mathrm{Mg})$ were determined using the EDTA titrimetric method and an inductively coupled plasma spectrometer (ICP-AES, Thermo, USA). Potential soil sucrase (SC), urease (UR), acid protease (ACPT) and glutaminase (GLS) activities were determined using the soil enzyme kit from Solarbio Science \& Technology Co. (Beijing, China). Acid (ACP) and alkaline phosphatase (ALP) activities were assayed by p-nitrophenyl phosphate disodium method (PNPP) at $\mathrm{pH}=6.5$ and 11 , respectively. Three parallel measurements were performed for each sample to minimize experimental errors.

\subsection{Soil quality evaluation}

The soil quality index (SQI) was evaluated by principal component analysis (PCA) with soil physico-chemical properties, enzyme activities and microelements as indicators. The determination procedure includes three steps: (1) selecting minimum data set (MDS) of indicators; (2) scoring the MDS indicators using a standard scoring function; (3) calculating soil quality index (SQI) of five forest types. First, a variety of soil properties including texture, bulk density, nutrients, enzyme activities and microelements were added to the indicator dataset, and correlation analysis was conducted. Secondly, all indicators were analyzed by PCA, with a varimax rotation to enhance interpretability of the uncorrelated components (Bernhard Flury \& Riedwyl, 1988). Only the principal components (PC) with eigenvalues ¿1 and absolute loading values [?]0.5 can identify representative MDS for further analysis (Bastida, Luis Moreno, Hernandez, \& Garcia, 2006). Third, to avoid information loss and data redundancy, the norm value of each indicator was calculated. For each PC, the selected indicators obtained the norm value within $10 \%$ of the maximum weighted load for the MDS1. When more than one indicator was retained in a PC, correlation analysis was conducted to determine whether these indicators were redundant (Andrews, Karlen, \& Mitchell, 2002). If high variables were highly correlated $(r$ [?]0.6) with the maximum value, only the highest factor loading was retained, and the rest would be eliminated from the dataset. Fourth, a standard scoring function was employed for each indicator in MDS2 (ranging from 0 to 1) (Andrews et al., 2002). The weight of an indicator was equal to the ratio of its communality with the sum of communalities of all indicators.

Type S:

$$
f\left(x_{i}\right)=\left\{\begin{array}{lr}
1.0 & , x_{i} \geq x_{2} \\
0.1+\frac{0.9\left(x_{i}-x_{1}\right)}{x_{2}-x_{1}} & , x_{1}<x_{i} x_{2} \\
0.1 & , x_{i} \leq x_{1}
\end{array}\right.
$$

(2) Type reverse S:

$$
f\left(x_{i}\right)=\left\{\begin{array}{cc}
0.1 & , x_{i} \geq x_{2} \\
0.1+\frac{0.9\left(x_{2}-x_{i}\right)}{x_{2}-x_{1}} & , x_{1}<x_{i} x_{2} \\
1.0 & , x_{i} \leq x_{1}
\end{array}\right.
$$


where $f(\mathrm{x})$ is the score of the indicator ranging from 0.1 to $1, \mathrm{X}$ is the value of soil indicator, $\mathrm{X}_{1}$ and $\mathrm{X}_{2}$ are the minimum and maximum values of indicator, respectively.

Finally, following scoring and weighting for all indicators in the MDS2, SQI was calculated as follows:

$\mathrm{SQI}=\sum_{i=1}^{n} W_{i} \times S_{i} \sum_{i=1}^{n} W_{i} \times F_{i}$

where SQI is the soil quality index ranging from 0 to $1.0, \mathrm{~W}_{\mathrm{i}}$ is the weight of each indicator, $\mathrm{F}_{\mathrm{i}}$ is the indicator score, and $\mathrm{n}$ is the number of indicators in the final MDS.

\subsection{DNA extraction, amplification, sequencing and data processing}

Soil total DNA was extracted from $0.3 \mathrm{~g}$ of homogenized soil samples using a DNA extraction kit (MoBio Laboratories Inc., CA, USA) following the manufacturer's instructions. The quantity and quality of the extracted DNA were assessed using a NanoDrop spectrophotometer (Thermo Fisher Scientific, MA, USA), and were further checked with $1 \%(\mathrm{w} / \mathrm{v})$ agarose gel. A primer set of ITS5-1737F (5'-GGAAGTAAAAGTCGTAACAAGG-3') and ITS2-2043R (5'-GCTGCGTTCTTCATCGATGC-3') with adaptors and barcodes was used to amplify fungal ITS hypervariable region (White, Bruns, Lee, \& Taylor, 1990). Polymerase chain reaction (PCR) followed the thermal-cycling conditions: initialization for 5 min at $94{ }^{\circ} \mathrm{C}, 30$ cycles of denaturation for $30 \mathrm{~s}$ at $94{ }^{\circ} \mathrm{C}$, annealing for $30 \mathrm{~s}$ at $52{ }^{\circ} \mathrm{C}$, and extension for $30 \mathrm{~s}$ at $72{ }^{\circ} \mathrm{C}$, followed by a final elongation for $10 \mathrm{~min}$ at $72{ }^{\circ} \mathrm{C}$. PCR products were mixed in equal density ratios according to the Gene Tools Analysis Software (Version4.03.05.0, SynGene), and were purified using an E.Z.N.A ${ }^{\circledR}$ Gel Extraction Kit (Omega Bio-Tek, Norcross, Georgia, USA). The resultant PCR products were sequenced on the IlluminaHiSeq2500 (250-bp paired-end reads) platform at Magigene Biotechnology Co., Ltd. (Guangzhou, China).

The paired-end raw reads were proceeded using Quantitative Insights Into Microbial Ecology (QIIME) pipeline (Caporaso et al., 2010) for quality filtering, trimming, and chimera checking. Low quality sequences (ambiguous bases, nucleotide mismatches, an average quality score $<20$, length $<100 \mathrm{bp}$, total expected errors $>0.1$ ) were filtered. After discarding chimeras and singletons, operational taxonomic units (OTUs) were identified using UPARSE with a similarity threshold of $97 \%$ (Edgar, 2013). Finally, representative sequences of fungal OTU were selected for taxonomic assignment by using BLAST against the UNITE database (http://unite.ut.ee/index.php) (Abarenkov et al., 2010), using the Ribosomal Database Project (RDP) classifier (Caporaso et al., 2010). Fungal functional guilds were tentatively assigned using the 'FUNGuild' algorithm (Nguyen et al., 2016). All raw sequences were deposited in the NCBI Sequence Read Archive (SRA) database under accession number SRR (SUB9976505).

\subsection{Statistical analyses}

A one-way analysis of variance (ANOVA) followed by a Duncan's test $(p<0.05)$ was applied to test the differences in soil properties, fungal diversity and abundance across five sites. PCA and Pearson's correlation was used to evaluate the SQI using the IBM SPSS software (SPSS Inc., Chicago, USA). For the sequence data, the $\alpha$ diversity indices including Observed species, Shannon-Wiener's diversity, Chao1 and species accumulation curves were calculated using Mothur and visualized in Origin 2018 software (OriginLab, USA). The $\beta$ diversity in the fungal community was visualized in CANOCO 5.0 software (Microcomputer Power, Ithaca, New York) by using non-metric multidimensional scaling (NMDS) ordinations based on Bray-Curtis distance. Network visualized by Cytoscape (Vailaya et al., 2007) was used to analyze the number of OTU which was cosmopolitan (present in all forest types), specific to forest or plantations (i.e., only detected in one forest type) or broadly dispersed (found in two or four sites). Linear discriminant analysis (LDA) effect size (LEfse) was conducted to identify the biomarkers between forest and plantations using an LDA score $>4$ and $p<0.05$ for the nonparametric Kruskal-Wallis test. A heatmap was conducted in R with the "pheatmap" package to compare the variation in dominant "funguilds" (top 35 in abundance). Relationships between soil parameters and the fungal community were performed with redundancy analysis (RDA) by using the CANOCO 5.0 software. Structural equation model (SEM) was further used to determine indirect or direct contributions of soil properties and fungal community with a multivariate approach using AMOS software 
(IBM SPSS AMOS 20.0.0). In this model, the Shannon index was selected as an informative estimate of taxonomic diversity for the fungal communities (Delgado-Baquerizo et al., 2016). The SEM fitness was examined on the basis of a non-significant chi-square test $\left(\chi^{2}\right), p$ value (i0.05), the goodness-of-fit index (GFI, good fit when GFI $\mathrm{L}_{0.9}$ ) and the root mean square error of approximation (RMSEA, good fit when RMSEA 0.05 ) (Byrne \& Erlbaums, 2009). The fit of additional indices of SEM is shown in Table S6.

\section{Results}

\subsection{Soil properties}

After forest conversion, soil BD was higher and SWC was lower in the plantations compared with the forest (Fig. 1a). The SOC and DOC contents were $83 \%$ and $39 \%$ lower, respectively (Fig. 1b, d). A similar decreasing trend was found for $\mathrm{TN}, \mathrm{NH}_{4}{ }^{+}$and $\mathrm{NO}_{3}{ }^{-}$contents (except Berry; Fig. 1b, d). Consequently, the soil C:N ratio (C/N) strongly dropped by 11.9 (Fig. 1b). However, the highest TP, TK and AP, AK contents were observed under Peach. Compared to the other three plantations, TP, TK and AP, AK in Peach was $26 \%, 12 \%, 88 \%$ and $43 \%$ higher, respectively (Fig. 1b, d). Compared with the forest, $\mathrm{Ca}^{2+}$ content in plantations was reduced by $43 \%$.

Soil enzyme activities decreased after conversion, including SC, ACPT, ACP, GLS, ACP and ALP (Fig. 1c). For instance, SC, ACPT and GLS activities declined up to $40 \%, 64 \%$ and $67 \%$, respectively (Fig. 1c). Similarly, soil phosphatase activities were lower in the plantations, and ACP and ALP activities declined by approximately $93 \%$ and $59 \%$, respectively (Fig. 1c). Likewise, with the exception of Berry (Fig.1c), the UR activities were lower in the plantation than in the forest (Fig. 1c).

\subsection{Soil quality index}

PCA results showed that the first three components with eigenvalues [?]1.0 explained $87 \%$ of the total variation of soil properties (Table S1). According to the Norm value, SOC, BD, DOC, TN, $\mathrm{NH}_{4}^{+}, \mathrm{C} / \mathrm{N}$, ACPT, ACP and ALP were the highly weighted variables in the PC1 and highly correlated with each other. Thus, SOC was selected in the PC1 with the highest eigenvector. Similarly, GLS and TP were selected for PC2 and PC3, respectively. In short, SOC, GLS and TP were the three important indicators selected for MDS2. The SQI was calculated after scoring and weighting the four indicators (Table S2). The SQI values derived with the MDS method ranged from 0.16 to 0.92. After conversion, the SQI of Forest decreased sharply by $65 \%$. Within four plantations, the highest values were observed in the Peach, the lowest in the Oil (Fig. 2).

\subsection{Diversity, composition and functional guilds of the fungal community}

After quality filtering, we obtained 1,252,350 sequences for downstream analysis (range, 83,490 \pm 369 reads per sample) from a total of $1,251,620$ raw sequencing reads. A total of 3,933 OTUs were clustered with [?] $97 \%$ identity from good-quality sequences. Rarefaction curves demonstrated that the sequencing depth was sufficient to capture species richness of the community (Fig. S1). Following forest conversion, Observed species, Shannon-Wiener and Chao1 indices of $\alpha$-diversity increased by $3.5 \%, 6.5 \%$ and $2.9 \%$, respectively. All indices were higher in Berry and Peach than the other three plantations $(p<0.05$; Fig. 3a, 3b, 3c). Moreover, Chao1, Observed species, and Shannon-Wiener indices increased with $\mathrm{pH}$, UR and $\mathrm{Mg}(p<0.05$; Table S3). According to NMDS analysis, the dissimilarity of the fungal community structure changed substantially after conversion (Fig. 3d).

In total, 15 fungal phyla and 696 genera were identified but only 4 phyla and 20 genera were recorded with relative abundances of over 1\%. Ascomycota, Basidiomycota, Glomeromycota and Zygomycota were dominant phyla, accounting for approximately $87 \%$ of the fungal sequences (Fig. 4a). After conversion, phyla such as Ascomycota, Zygomycota, and Glomeromycota increased, but Basidiomycota and Rozellomycota decreased by $57 \%$ and $32 \%$, respectively (Fig. 4a). Ascomycota increased with TK, but decreased with $\mathrm{NO}_{3}{ }^{-}\left(p<0.05\right.$; Table S5). Basidiomycota declined with SOC, DOC, C/N, $\mathrm{NH}_{4}{ }^{+}$, GLS and ACP, and Rozellomycota fell with $\mathrm{NO}_{3}{ }^{-}$, UR, GLS and Ca, while Glomeromycota increased with BD $(p<0.05$; Table S5). 
At the genus level, relative abundance ofPseudochaetosphaeronema and Russula decreased by approximately 99\%, while Pseudophialophora, Rhytisma andLepidostroma increased after conversion (Fig. 4b; Table S4).

Most fungi were classified as saprotrophs (35\%), undefined saprotrophs (29\%) or ectomycorrhizal fungi (13\%). Comparisons within the top 35 guilds revealed that three functional guilds (ectomycorrhizal, wood saprotroph, fungal parasites) were more abundant in Forest than in plantations, whereas undefined saprotrophs, arbuscular mycorrhizal, bryophyte parasite and plant pathogen fungi were enriched in plantations (Fig. 5).

The majority of the top 50 OTUs were either broadly dispersed across five sites (32\%) or only occurred in the plantations (32\%) (Fig. 6). Specific OTUs for Forest, Oil, Peach, Berry and Fir plantations were six, five, one, four and two, respectively. Specifically,Pseudochaetosphaeronema OTU_4 and Russula OTU_7 were distinct from others for Forest. Biscogniauxia OTU_55 and Inocybe OTU_25 were special to Oil. Cistella OTU_100 was unique to Peach. Simplicillium OTU_48, SubulicystidiumOTU_125, Dendrochytridium OTU_90 and MelanogasterOTU_88 were four particular taxa for Berry. Lepidostroma OTU_38 and Tomentella OTU_17 were specific for Fir (Fig. 6). LDA analysis showed that the Agaricomycetes class and Russulaceae family were identified as biomarkers between Forest and Oil, Berry, respectively. Compared with the Forest, Russulales order (belonging to Basidiomycota) was identified as a biomarker in Peach and Fir plantations (Fig. S2).

\subsection{Effects of key soil properties on fungal community composition}

Soil properties explained $37.4 \%$ of the total variance of the fungal community composition at the OTU level (RDA analysis). The community structure of Forest was more closely associated with soil SWC, SOC, DOC, C/N, TN, and $\mathrm{NH}_{4}{ }^{+}$, and activities of SC, ACPT, ACP, and ALP (Fig. 7a). By contrast, those of the Berry and Peach were more strongly affected by $\mathrm{pH}$, TP, AP, $\mathrm{NO}_{3}{ }^{-}, \mathrm{Ca}, \mathrm{Mg}$, TK, AK, BD, GLS and UR activities $(p<0.05)$. Pearson's correlation indicated that the dominant phyla had strong correlation with soil quality indicators (Fig. 7b; Table S5). For instance, the relative abundance of Basidiomycota decreased with the reduction of SOC content $(p=0.033)$ and GLS $(p=0.042)$.

The SEM model indicated that the key predictors collectively accounted for $42 \%$ of the variation in fungal community diversity (Fig. 8). This model depended on the contents of $\mathrm{pH}$, TP, TN and SOC affected by conversion. In particular, fungal diversity was directly and positively mediated by the key soil quality indicators including TP (path coefficient $=0.54, p<0.01$ ) and $\mathrm{pH}$ (path coefficient $=0.51, p<0.001$ ), and probably indirectly affected by the contents of SOC, DOC and TN (Fig. 8). The fungal diversity also had a direct negative impact on DOC contents (path coefficient $=-0.19, p<0.001$ ), SC (path coefficient $=-0.38$, $p<0.01$ ) and ALP activities (Fig. 8). The key soil quality indicator SOC was positively and directly related to TN, DOC and SC activities (Table S7), and it also increased with ALP activities via SC. However, SOC exerted a direct positive impact on TP (Fig. 8).

\section{Discussion}

\subsection{Effects of forest conversion on soil quality}

The soil C, N contents dropped by $83 \%$ and $59 \%$ after conversion, respectively (Fig. 1), similar to previous studies that were focused on rainforest and temperate forest conversion into monoculture plantations (Guillaume et al., 2015; Yang et al., 2018). Firstly, soil erosion increased when understory vegetation and litter layer were removed after conversion, coupled with a large amount of precipitation in the region. These factors caused a sharp drop in C and N contents (Guillaume et al., 2015). Secondly, the decomposition of SOC increased due to nutrient release from the dead or burnt biomass, and the labile organic matter released from destroyed soil aggregates (Berhe, Harte, Harden, \& Torn, 2007). Therefore, soil SOC content decreased following conversion. Third, $\mathrm{C}$ and $\mathrm{N}$ were reduced in plantations because low plant diversity prevented the formation of developed organic horizons, and reduced the input of labile organic compounds, leading to a decrease in microbial biomass (Mcguire et al., 2015). In contrast, soil $\mathrm{pH}$ increased after conversion, which was ascribed to three factors: 1) Conversion reduces plant species, resulting in a decline in root and ectomycorrhizal exudates which contain a lot of organic acids (Grayston, Vaughan, \& Jones, 1997). Thus, 
soil $\mathrm{pH}$ increased after conversion. 2) Soil erosion removes the surface layer, which is usually more acidic than the subsoil. 3) The increase of exchangeable cations results in an increase in soil $\mathrm{pH}$, as a fertilizer following conversion (Tripathi et al., 2016). In addition, soil TP, AP, TK, AK were the highest in the Peach plantation (Fig. 1) because of intensive application of mineral and organic fertilizers.

Compared with Forest, the enzymatic activity of SC, ACPT, GLS, UR, ACP and ALP decreased in plantations (Fig. 1). Soil SC is a C-degrading enzyme involved in organic matter hydrolysis. Thus, the SC activities declined with the reduction of SOC after conversion. Soil ACPT, UR and GLS are key enzymes involved in $\mathrm{N}$ mineralization. ACPT acts on proteolysis and breaks down organic $\mathrm{N}$ such as proteins and peptides into amino acids (Watanabe, 2010). UR converts organic $\mathrm{N}$ to mineral nitrogen that can be used by plants and microorganisms (Fraser, Hallett, Wookey, Hartley, \& Hopkins, 2013). In the Forest, high SOC content accelerates $\mathrm{N}$ mineralization, resulting in higher $\mathrm{N}$ mineralization activity, including ACPT and UR (Yang, Yang, \& Yu, 2018). Soil GLS involves the hydrolysis of L-glutamine to produce L-glutamic acid and $\mathrm{NH}_{3}$, and its activity is positively correlated with organic $\mathrm{C}$ and total $\mathrm{N}$ (Frankenberger \& Tabatabai, 1991). Thus, the decrease in GLS activity is attributed to the drop in SOC and TN contents in plantations. After conversion, the phosphatase activity decreased with the increase of AP content. Compared with plantations, lower AP stimulated the microbial community to secrete phosphatase to mobilize P from organic sources, leading to higher phosphatase activity in the Forest (Wu et al., 2019).

The decline in soil quality after conversion, revealed by the SQI, showed that GLS was the biggest contributor to SQI, followed by SOC and TP (Fig. 2, Table S2). GLS is a key enzyme of N metabolism, as it catalyzes the hydrolysis of $\mathrm{NH}_{3}$ group from amino acid and degrades L-glutamine into L-glutamic acid and ammonium ions, which maybe a reliable indicator of soil fertility (Kanazawa \& Kiyota, 2000). Hence, this enzyme could be used as a biological indicator of SQI in subtropical areas. SOC is often used as a proxy of soil quality and productivity due to its key role in multiple soil processes such as nutrient cycling as well as plant and microbial growth (Raiesi, 2017). A big decrease in GLS activities and SOC contents was responsible for the sharp drop in SQI after conversion. Forest conversion accelerated soil erosion, reduced organic matter inputs and C, N contents, resulting in a decrease in SQI. TP was another key indicator that contributed to SQI (Zhang et al., 2019). Among the four plantations, SQI of Peach and Berry was superior than the other two, indicating that fertilization was beneficial for soil quality after conversion by increasing TP contents.

\subsection{Effects of forest conversion on fungal communities}

After forest conversion, $\alpha$-diversity of fungi increased in Berry and Peach plantations (Fig. 3a-c), and there were significant differences in community structure among the five types of plantations (Fig. 3d). The increase of $\alpha$-diversity was consistent with the conversion of which forest to which plantation (Nakayama et al., 2019). We explain this as follows: 1) Acidity reduced the taxonomic diversity of the arbuscular mycorrhiza fungi (AM) by decreasing sporulation (Coughlan, Dalpé, Lapointe, \& Piché, 2000). Hence, the gradual increase in soil pH led to a higher diversity in plantations (Fig. 3a-c, Fig. 8). 2) Fertilization was responsible for the increase of $\alpha$-diversity in Berry and Peach. The continuous application of manure increased fungal biomass and diversity by increasing substrate variety and $\mathrm{C}$ input (Kamaa et al., 2011). The exogenous fungi from the manure (organic resources) may increase fungal diversity of plantation (Sun et al., 2016). According to the $\beta$-diversity, notable divergence was observed in the composition between Forest and four plantations (Fig. 3d). Forest conversion affects fungal community structure via changes in soil chemical properties (e.g., pH, C, N contents), root exudates and litter input (Prescott \& Grayston, 2013).

Due to specific functional attributes and survival strategies, the abundance of dominant fungi responded differently to forest conversion (Fig. 4, 6). For instance, the abundance of Basidiomycota decreased while that of Ascomycota and Zygomycota increased. We can characterize these fungi based on Grime's C-S-R (Competitor, Stress-tolerant, Ruderal) life history strategy to explain succession dynamics and the spatial structure of fungal assemblages (Chagnon, Bradley, Maherali, \& Klironomos, 2013; Grime, 1979). Zygomycota (R-strategists) are primary saprotrophic fungi with ruderal strategies, which are only active in habitats with low levels of competition and stress. They are characterized by a short growth period, high reproductive potential, and effective use of accessible substrates (Cooke \& Rayner, 1984). Thus, Zygomycota are 
more abundant in plantations with low $\mathrm{C}$ and $\mathrm{N}$ content. Basidiomycota and Ascomycota are secondary saprotrophic fungi, and their $c b h I$ gene is a reliable indicator of cellulolytic ability. Both fungi groups can degrade part of plant residues and promote soil C accumulation (Stursova, Zifcakova, Leigh, Burgess, \& Baldrian, 2012). By contrast, most Basidiomycota (C-strategists) are white and brown rot fungi, which are late-successional and oligotrophic species with slow growth and favor resource-rich conditions and better substrate quality (high $\mathrm{C} / \mathrm{N}$ ). They are usually involved in decomposition of lignified plant detritus (Lundell, Makela, \& Hilden, 2010). In addition, the lignin content in old forest litter is high (Osono, 2006). Therefore, $\mathrm{C}$-strategists Basidiomycota decrease with reduction of $\mathrm{C} / \mathrm{N}$ ratio and litter after conversion. Subsequently, Basidiomycota such as the typical ectomycorrhizal group (Russula) and other genera belonging to the Basidiomycota declined sharply. In contrast, Ascomycotas are S-strategy fungi, with survival related stress tolerance characteristics, and use resources more efficiently under low-nutrient conditions. So they exhibit a more stress-tolerant strategy to C substrate than Basidiomycetes (Wang et al., 2021). The Ascomycotas are mainly soft rot fungi that can decompose complex organic matters such as cellulose, hemicellulose and the lignin in the soil (Stursova et al., 2012). As a fast-growing copiotrophic fungi, the S-strategists Ascomycota increased with stressful conditions (low $\mathrm{C}, \mathrm{N}$ contents) in plantations. Thereby, the abundance of genera affiliated Ascomycota:Pseudophialophora andRhytisma increased. Moreover, among the root-associated fungi, the change in the abundance of Ascomycota related to Basidiomycota also implied that the ratio of ericoid mycorrhizal fungi (mainly Ascomycota) and ectomycorrhizal (mainly Basidiomycota) had changed (Sterkenburg, Bahr, Brandstrom, Clemmensen, \& Lindahl, 2015).

\subsection{Main drivers of fungal community under forest conversion}

According to the RDA analysis, shifts of fungal composition were associated with changes in key soil quality properties, such as SOC (Fig. 7, Table S5). Fungal diversity was directly regulated by the soil pH, TP and TN, but indirectly affected by SOC according to the SEM (Fig. 8). Soil pH directly shapes the fungal community by affecting nutrients uptake over the cell plasma membrane, secretase activity or mycorrhizal colonization (Deacon, 2006), or affecting multiple soil chemical parameters such as ion concentrations, base cations and available P. For example, an increase in $\mathrm{pH}$ reduces bioavailable $\mathrm{P}$ pool via decreased production of extracellular enzymes used by soil microorganisms to access organic phosphate, and then affects mycorrhizal colonization, biomass and fungal community structure (Carrino-Kyker et al., 2016). Base cation (e.g., $\mathrm{Ca}^{2+}$ ) also increased AM (mostly belonging to Glomeromycota) colonization by affecting spore germination, mycelia production and hyphal regrowth (Coughlan et al., 2000; Hepper, 1984). Moreover, $\mathrm{Ca}^{2+}$ influences the turnover rate of soil organic matter, and increases colonization and biomass of Ectomycorrhizal (ECM) fungi, particular Basidiomycota (Põlme et al., 2013). Alternatively, soil pH had an indirect effect on the fungal community. Since the more acidic soil in Forest inhibits the growth of bacteria, fungi are more competitive in the use of substrates, thus establishing a variety of niches (Gunina, Smith, Godbold, Jones, \& Kuzyakov, 2017).

SOC, TN and TP were important regulators of fungal communities after forest conversion (Fig. 8). As non-autotrophic microorganisms, fungi mainly rely on $\mathrm{C}$ sources from fallen leaves, wood detritus and root exudates, which are the three key ways that aboveground plants affect soil fungal communities. Firstly, litter quality affected degradation rates and composition of saprotrophic (mainly Ascomycota) and ECM fungi (mainly Basidiomycota) (Prescott \& Grayston, 2013). Secondly, the reduction of wood detritus led to a decline in the abundance of Basidiomycota, which mainly decomposed lignin (Cooke \& Rayner, 1984). Thirdly, some $\mathrm{C}$ in soil came from root exudates, including primary metabolites (sugars, amino acids and organic acids) and secondary metabolites (Jones, Hodge, \& Kuzyakov, 2004). The reduction of organic substrates in root exudates may alter the fungal community composition (Prescott \& Grayston, 2013). Hence, as the plant diversity decreases, and understory plants and litter are removed after conversion, the diversity of organic substrates entering the soil is reduced, thereby reducing the ability to establish highly diverse heterotrophic fungi (Peay, Baraloto, \& Fine, 2013). Moreover, high levels of soil erosion in the plantations reduced the SOC and TN stock, and accelerated SOC mineralization and mineral $\mathrm{N}$ leaching, resulting in lowered $\mathrm{C}$ and N contents (Guillaume et al., 2015). Dominant taxa fungal growth was consequentially reduced. For instance, the abundance of Basidiomycota decreased with the decrease of $\mathrm{C}$ and $\mathrm{N}$ content under plantations 
(Lauber, Strickland, Bradford, \& Fierer, 2008). In addition, P is a key regulator of the biogeographical pattern of fungal communities. Higher $\mathrm{P}$ content increases plant root growth, mycelia development and mycorrhizas, especially for special functional groups such as AM and ECM fungi, thereby enhancing fungal diversity (Baldrian, 2017). Therefore, after the forest was converted into plantations, the synchronization effect caused changes in the biodiversity of the fungal community.

\section{Conclusions}

The conversion from natural forest to monoculture plantations decreased $\mathrm{C}$ and $\mathrm{N}$ contents and related enzymes activities (such as sucrase, acid protease, urease, glutaminase, acid and alkaline phosphatase activities), thereby reducing soil quality. The conversion resulted in markedly differences in the structure of the fungal community between Forest and plantations, and increased microbial $\alpha$-diversity. According to the life history classification system based on functional traits - Grime's C-S-R (competitor, stress-tolerator, ruderal) life history framework, forest conversion decreased the abundance of dominant fungal taxa including Basidiomycota (C-strategists), but increased that in Ascomycota (S-strategists) and Zygomycota (R-strategists). The decrease of C-strategists Basidiomycota indicated that forest conversion had a negative impact on the fungal lignin decomposition ability and competitive intensity, especially for oligotrophic taxa. The increase of S-strategists Ascomycota and R-strategists Zygomycota demonstrated that some taxa with stress-tolerating and ruderal survival strategies, such as copiotrophic fungi, maximize occupation and exploitation of available resources after conversion. Correspondingly, Pseudophialophora, Rhytisma and other genera (mostly belonging to Ascomycota) increased, while Russula (mostly belonging to Basidiomycota) decreased. Correlation analysis showed that, in addition to soil $\mathrm{pH}$, the key indicators of SQI, including organic carbon, glutaminase, and phosphorus, were main drivers for fungal community characteristics in subtropical forest conversion. To conclude, forest conversion to monoculture plantations decreased soil quality, but increased the dominance of $\mathrm{S}$ and $\mathrm{R}$ strategists in a more diverse fungal community, retarding lignin decomposition and increasing the depletion of available resources.

\section{Acknowledgment}

This study was supported by the Key Research and Development program of Hunan Province (2020NK2022), National Natural Science Foundation of China (32171761), Scientific Innovation Fund for Post-graduates of Central South University of Forestry and Technology (CX20191006, CX202102023), and Special Funding for Innovative Construction in Hunan Province (2021ZK4226). Thanks also to the staff in Lutou National Station for Scientific Observation and Research of Forest Ecosystems and National Engineering Laboratory of Applied Technology for Forestry \& Ecology in Southern China for field sampling and laboratory analysis. We appreciate the West-Siberian Interregional Science and Education Center's (project 89-DON) and CarboRus project (075-15-2021-610). Special thanks to the Ministry of Education of the People's Republic of China providing Yakov Kuzyakov the Changjiang Professorship Award. The publication was supported by the Government Program of Competitive Growth of Kazan Federal University and with the support of the "RUDN University Strategic Academic Leadership program".

Declaration of interests

The authors declare that they have no known competing financial interests or personal relationships that could have appeared to influence the work reported in this paper.

\section{R E F E R E N C E S}

Abarenkov, K., Nilsson, R. H., Larsson, K. H., Alexander, I. J., Eberhardt, U., Erland, S., Pennanen, T. (2010). The UNITE database for molecular identification of fungi-recent updates and future perspectives.New Phytologist, 186 (2), 281-285. https://10.1111/j.1469-8137.2009.03160.x

Andrews, S. S., Karlen, D. L., \& Mitchell, J. P. (2002). A comparison of soil quality indexing methods for vegetable production systems in Northern California. Agriculture Ecosystem E3 Environment ,90 (1), 25-45. https://10.1016/S0167-8809(01)00174-8 
Armenise, E., Redmile-Gordon, M. A., Stellacci, A. M., Ciccarese, A., \& Rubino, P. (2013). Developing a soil quality index to compare soil fitness for agricultural use under different managements in the Mediterranean environment. Soil \& Eillage Research , 130 , 91-98. https://10.1016/j.still.2013.02.013

Baldrian, P. (2017). Microbial activity and the dynamics of ecosystem processes in forest soils. Current Opinion In Microbiology, 37, 128-134. https://10.1016/j.mib.2017.06.008

Bastida, F., Luis Moreno, J., Hernández, T., \& García, C. (2006). Microbiological degradation index of soils in a semiarid climate.Soil biology \& biochemistry , 38 (12), 3463-3473. https://10.1016/j.soilbio.2006.06.001

Berhe, A. A., Harte, J., Harden, J. W., \& Torn, M. S. (2007). The Significance of the Erosion-induced Terrestrial Carbon Sink. Bioscience ,57 (4). https://10.1641/B570408

Bernhard Flury, \& Riedwyl, H. (1988). Multivariate Statistics. A Practical Approach . London: Chapman and Hall.

Bünemann, E. K., Bongiorno, G., Bai, Z., Creamer, R. E., De Deyn, G., de Goede, R., Brussaard, L. (2018). Soil quality-A critical review. Soil Biology and Biochemistry , 120 , 105-125. https://10.1016/j.soilbio.2018.01.030

Byrne, B. M., \& Erlbaums, L. (2009). Structural equation modeling with AMOS: basic concepts, applications, and programming. London: Routledge.

Caporaso, J. G., Kuczynski, J., Stombaugh, J., Bittinger, K., Bushman, F. D., \& Costello, E. E. A. (2010). QIIME allows analysis of high-throughput community sequencing data. Nature Methods , 7 , 335-336. https://10.1038/nmeth0510-335

Carrino-Kyker, S. R., Kluber, L. A., Petersen, S. M., Coyle, K. P., Hewins, C. R., Deforest, J. L., Anderson, I. (2016). Mycorrhizal fungal communities respond to experimental elevation of soil $\mathrm{pH}$ and $\mathrm{P}$ availability in temperate hardwood forests. FEMS microbiology ecology,92 (3), w24. https://10.1093/femsec/fiw024

Chagnon, P., Bradley, R. L., Maherali, H., \& Klironomos, J. N. (2013). A trait-based framework to understand life history of mycorrhizal fungi.Trends in Plant Science , 18 (9), 484-491. https://10.1016/j.tplants.2013.05.001

Cooke, R. C., \& Rayner, A. (1984). Ecology of saprotrophic fungi . London: Longman.

Coughlan, A. P., Dalpé, Y., Lapointe, L., \& Piché, Y. (2000). Soil pH-induced changes in root colonization, diversity, and reproduction of symbiotic arbuscular mycorrhizal fungi from healthy and declining maple forests. Canadian Journal of Forest Research , 30 (10), 1543-1554. https://10.1139/cjfr-30-10-1543

Deacon, J. (2006). Fungal biology. Mycological Research , 110 (1), 121-122. https://10.1016/j.mycres.2005.11.002

Delgado-Baquerizo, M., Maestre, F. T., Reich, P. B., Jeffries, T. C., Gaitan, J. J., Encinar, D., Singh, B. K. (2016). Microbial diversity drives multifunctionality in terrestrial ecosystems. Nature Communications , 7 (1), 1-8. https://10.1038/ncomms10541

Doran, J. W., \& Parkin, T. B. (1996). Quantitative indicators of soil quality: a minimum data set. Soil Science Society of America, 25-37. https://10.2136/sssaspecpub49.c2

Duhamel, M., Wan, J., Bogar, L. M., Segnitz, R. M., Duncritts, N. C., \& Peay, K. G. (2019). Plant selection initiates alternative successional trajectories in the soil microbial community after disturbance.Ecological Monographs , 89 (3), e1367. https://10.1002/ecm.1367

Edgar, R. C. (2013). UPARSE: highly accurate OTU sequences from microbial amplicon reads. Nature Methods , 10 (10), 996-998. https://10.1038/nmeth.2604

FAO (2015). Global Forest Resources Assessment 2015: how are the world's forests changing? In: Food and Agriculture Organization of the United Nations. 
Frankenberger, W., \& Tabatabai, M. A. (1991). L-glutaminase activity of soil.Soil Biology and Biochemistry , 23 (9), 869-874. https://10.1016/0038-0717(91)90099-6

Fraser, F. C., Hallett, P. D., Wookey, P. A., Hartley, I. P., \& Hopkins, D. W. (2013). How do enzymes catalysing soil nitrogen transformations respond to changing temperatures? Biology and Fertility of Soils, 49 (1), 99-103. https://10.1007/s00374-012-0722-1

Grayston, S. J., Vaughan, D., \& Jones, D. (1997). Rhizosphere carbon flow in trees, in comparison with annual plants: the importance of root exudation and its impact on microbial activity and nutrient availability. Applied Soil Ecology , 5 (1), 29-56. https://10.1016/S0929-1393(96)00126-6

Grime, J. P. (1979). Plant strategies and vegetation processes. Biologia Plantarum , 23 (4), 254. https://10.1007/BF02895358

Guillaume, T., Damris, M., \& Kuzyakov, Y. (2015). Losses of soil carbon by converting tropical forest to plantations: erosion and decomposition estimated by 813C. Global Change Biology , 21 (9), 3548-3560. https://10.1111/gcb.12907

Gunina, A., Smith, A. R., Godbold, D. L., Jones, D. L., \& Kuzyakov, Y. (2017). Response of soil microbial community to afforestation with pure and mixed species. Plant and Soil , 412 (1-2), 357-368. https://10.1007/s11104-016-3073-0

Hepper, C. M. (1984). Regulation of spore germination of the vesicular-arbuscular mycorrhizal fungus Acaulospora laevis by soil pH.Transactions of the British Mycological Society , 83 (1), 154-156. https://10.1016/S0007-1536(84)80258-2

Johnson, N. C., Rowland, D. L., Corkidi, L., \& Allen, E. B. (2008). Plant winners and losers during grassland N-eutrophication differ in biomass allocation and mycorrhizas. Ecology , 89 (10), 2868-2878. https://10.1890/07-1394.1

Jones, D. L., Hodge, A., \& Kuzyakov, Y. (2004). Plant and mycorrhizal regulation of rhizodeposition. New Phytologist, 163 (3), 459-480. https://10.1111/j.1469-8137.2004.01130.x

Kamaa, M., Mburu, H., Blanchart, E., Chibole, L., Chotte, J., Kibunja, C., \& Lesueur, D. (2011). Effects of organic and inorganic fertilization on soil bacterial and fungal microbial diversity in the Kabete long-term trial, Kenya. Biology and Fertility of Soils , 47 (3), 315-321. https://10.1007/s00374-011-0539-3

Kanazawa, S., \& Kiyota, H. (2000). Effect of fertilizer and manure application on Lglutaminase and L-asparaginase activities in soils.Soil science and plant nutrition , 46 (3), 741-744. https://10.1080/00380768.2000.10409139

Kerfahi, D., Tripathi, B. M., Dong, K., Go, R., \& Adams, J. M. (2016). Rainforest conversion to rubber plantation may not result in lower soil diversity of bacteria, fungi, and nematodes. Microbial ecology ,72 (2), 359-371. https://10.1007/s00248-016-0790-0

Krashevska, V., Klarner, B., Widyastuti, R., Maraun, M., \& Scheu, S. (2015). Impact of tropical lowland rainforest conversion into rubber and oil palm plantations on soil microbial communities. Biology and fertility of soils , 51 (6), 697-705. https://10.1007/s00374-015-1021-4

Lan, G., Wu, Z., Yang, C., Sun, R., Chen, B., \& Zhang, X. (2021). Forest conversion alters the structure and functional processes of tropical forest soil microbial communities. Land Degradation 8$\}$ Development, 32 (2), 613-627. https://10.1002/ldr.3757

Lauber, C. L., Strickland, M. S., Bradford, M. A., \& Fierer, N. (2008). The influence of soil properties on the structure of bacterial and fungal communities across land-use types. Soil Biology and Biochemistry, 40 (9), 2407-2415. https://10.1016/j.soilbio.2008.05.021

Liu, T., Wu, X., Li, H., Alharbi, H., Wang, J., Dang, P., Yan, W. (2020). Soil organic matter, nitrogen and $\mathrm{pH}$ driven change in bacterial community following forest conversion. Forest Ecology and Management , 477 
, 118473. https://10.1016/j.foreco.2020.118473

Lundell, T. K., Makela, M. R., \& Hilden, K. (2010). Lignin-modifying enzymes in filamentous basidiomycetes-ecological, functional and phylogenetic review. Journal of basic microbiology , 50 (1), 520. https://10.1002/jobm.200900338

Mcguire, K. L., D Angelo, H., Brearley, F. Q., Gedallovich, S. M., Babar, N., Yang, N., Fierer, N. (2015). Responses of soil fungi to logging and oil palm agriculture in Southeast Asian tropical forests. Microbial Ecology , 69 (4), 733-747. https://10.1007/s00248-014-0468-4

Nakayama, M., Imamura, S., Taniguchi, T., \& Tateno, R. (2019). Does conversion from natural forest to plantation affect fungal and bacterial biodiversity, community structure, and co-occurrence networks in the organic horizon and mineral soil? Forest Ecology and Management ,446 , 238-250. https://10.1016/j.foreco.2019.05.042

Nguyen, N. H., Song, Z., Bates, S. T., Branco, S., Tedersoo, L., Menke, J., Kennedy, P. G. (2016). FUnGuild: An open annotation tool for parsing fungal community datasets by ecological guild. Fungal Ecology ,20 , 241-248. https://10.1016/j.funeco.2015.06.006

Osono, T. (2006). Role of phyllosphere fungi of forest trees in the development of decomposer fungal communities and decomposition processes of leaf litter. Canadian Journal of Microbiology, 52 (8), 701-716. https://10.1139/w06-023

Peay, K. G., Baraloto, C., \& Fine, P. V. A. (2013). Strong coupling of plant and fungal community structure across western Amazonian rainforests. The ISME Journal , 7 (9), 1852-1861. https://10.1038/ismej.2013.66

Põlme, S., Bahram, M., Yamanaka, T., Nara, K., Dai, Y. C., Grebenc, T., Tedersoo, L. (2013). Biogeography of ectomycorrhizal fungi associated with alders (Alnus spp.) in relation to biotic and abiotic variables at the global scale. New phytologist , 198 (4), 1239-1249. https://10.1111/nph.12170

Prescott, C. E., \& Grayston, S. J. (2013). Tree species influence on microbial communities in litter and soil: Current knowledge and research needs.Forest Ecology and Management , 309 , 19-27. https://10.1016/j.foreco.2013.02.034

Raiesi, F. (2017). A minimum data set and soil quality index to quantify the effect of land use conversion on soil quality and degradation in native rangelands of upland arid and semiarid regions. Ecological Indicators , 75 , 307-320. https://10.1016/j.ecolind.2016.12.049

Steidinger, B. S., Crowther, T. W., Liang, J., Van Nuland, M. E., Werner, G. D. A., Reich, P. B., Peay, K. G. (2019). Climatic controls of decomposition drive the global biogeography of forest-tree symbioses. Nature ,569 (7756), 404-408. https://10.1038/s41586-019-1128-0

Sterkenburg, E., Bahr, A., Brandstrom, D. M., Clemmensen, K. E., \& Lindahl, B. D. (2015). Changes in fungal communities along a boreal forest soil fertility gradient. New phytologist , 207 (4), 1145-1158. https://10.1111/nph.13426

Stursova, M., Zifcakova, L., Leigh, M. B., Burgess, R., \& Baldrian, P. (2012). Cellulose utilization in forest litter and soil: identification of bacterial and fungal decomposers. FEMS microbiology ecology ,80 (3), 735746. https://10.1111/j.1574-6941.2012.01343.x

Sun, R., Dsouza, M., Gilbert, J. A., Guo, X., Wang, D., Guo, Z., Chu, H. (2016). Fungal community composition in soils subjected to long-term chemical fertilization is most influenced by the type of organic matter.Environmental Microbiology , 18 (12), 5137-5150. https://10.1111/1462-2920.13512

Tripathi, B. M., Edwards, D. P., Mendes, L. W., Kim, M., Dong, K., Kim, H., \& Adams, J. M. (2016). The impact of tropical forest logging and oil palm agriculture on the soil microbiome. Molecular Ecology ,25 (10), 2244-2257. https://10.1111/mec.13620 
Uroz, S., Buée, M., Deveau, A., Mieszkin, S., \& Martin, F. (2016). Ecology of the forest microbiome: Highlights of temperate and boreal ecosystems.Soil Biology and Biochemistry , 103 , 471-488. https://10.1016/j.soilbio.2016.09.006

Vailaya, A., Cline, M. S., Workman, C., Bader, G. D., Isserlin, R., Creech, M., Ideker, T. (2007). Integration of biological networks and gene expression data using Cytoscape. Nature protocols , 2 (10), 2366-2382. https://10.1038/nprot.2007.324

Van der Linde, S., Suz, L. M., Orme, C. D. L., Cox, F., Andreae, H., Asi, E., Bidartondo, M. I. (2018). Environment and host as large-scale controls of ectomycorrhizal fungi. Nature , 558 (7709), 243-248. https://10.1038/s41586-018-0189-9

Wang, X., Zhang, W., Liu, Y., Jia, Z., Li, H., Yang, Y., Zhang, X. (2021). Identification of microbial strategies for labile substrate utilization at phylogenetic classification using a microcosm approach. Soil Biology and Biochemistry , 153 , 107970. https://10.1016/j.soilbio.2020.107970

Watanabe, K. (2010). Detection of protease genes in field soil applied with liquid livestock feces and speculation on their function and origin. Soil Science \& Plant Nutrition, 55 (1), 42-52. https://10.1111/j.17470765.2008.00323.x

White, T. J., Bruns, T., Lee, S., \& Taylor, J. (1990). 38-Amplification and direct sequencing of fungal ribosomal RNA genes for phylogenetics. In: Innis, M. A., Gelfand, D. H., Sninsky, J. J., \& White, T. J. (Eds.),PCR Protocols (pp. 315-322). San Diego: Academic Press.

Wu, H., Xiang, W., Ouyang, S., Forrester, D. I., Zhou, B., Chen, L., Peng, C. (2019). Linkage between tree species richness and soil microbial diversity improves phosphorus bioavailability. Functional Ecology , 33 (8), 1549-1560. https://10.1111/1365-2435.13355

Yakov, Kuzyakov, A., Gunina, K., Zamanian, J., Tian, Y., X, L., Alharbi, L. (2020). New approaches for evaluation of soil health, sensitivity and resistance to degradation. Frontiers of Agricultural Science and Engineering , v.7 (03), 56-62. https://10.15302/J-FASE-2020338

Yang, K., Zhu, J., Xu, S., \& Zheng, X. (2018). Conversion from temperate secondary forests into plantations (Larix spp.): Impact on belowground carbon and nutrient pools in northeastern China. Land Degradation $\mathcal{E}$ Development , 29 (11), 4129-4139. https://10.1002/ldr.3169

Yang, M., Yang, D., \& Yu, X. (2018). Soil microbial communities and enzyme activities in seabuckthorn (Hippophae rhamnoides) plantation at different ages. PLoS One, 13 (1), e190959. https://10.1371/journal.pone.0190959

Zarafshar, M., Bazot, S., Matinizadeh, M., Bordbar, S. K., Rousta, M. J., Kooch, Y., Negahdarsaber, M. (2020). Do tree plantations or cultivated fields have the same ability to maintain soil quality as natural forests?Applied Soil Ecology , 151 , 103536. https://10.1016/j.apsoil.2020.103536

Zhang, Y., Xu, X., Li, Z., Liu, M., Xu, C., Zhang, R., \& Luo, W. (2019). Effects of vegetation restoration on soil quality in degraded karst landscapes of southwest China. Science of The Total Environment ,650 , 2657-2665. https://10.1016/j.scitotenv.2018.09.372

\section{Hosted file}

Figures.docx available at https://authorea.com/users/453032/articles/550974-soilquality-and-c-s-r-fungal-communities-in-monoculture-plantations-after-conversion-fromsubtropical-forest 